\title{
Mudhol Dog Rearing - A Novel Approach to Rural Entrepreneurship
}

\author{
B.G. Shambhulingappa ${ }^{1}$, K. Vasudeva Naik ${ }^{2 *}$ and Sureshkumar $^{3}$ \\ ${ }^{1}$ Animal Husbandry Polytechnic, Shiggaon, India \\ ${ }^{2}$ COA, B. Gudi, UAS, Raichur, India \\ ${ }^{3}$ Karnataka Veterinary, Animal and Fisheries Sciences University, Bidar, India \\ *Corresponding author:
}

\section{A B S T R A C T}

Keywords

Mudhol dog,

Breeding,

Puppies, Feed, Dog

rearing practices

Article Info

Accepted:

15 July 2018

Available Online:

10 August 2018
Animal husbandry is an integral component of socio-economic fabric of our country. Animal husbandry contributes about 3.92\% to the country's GDP. One important thing that distinguishes them from other common exotic breeds like German Shephard, Labrador, Doberman etc. The income of more than Rs. 50000/- can be earned by a farmer by rearing one female Mudhol hound dog, which can be still increased by reducing the cost of feed and increasing the sale price of puppies. With the knowledge of entrepreneurship building, proper marketing strategies and adopting scientific dog rearing practices, a farmer can develop an enterprise of Mudhol hound dog rearing in rural areas.

\section{Introduction}

Animal husbandry is an integral component of socio-economic fabric of our country. Animal husbandry contributes about $3.92 \%$ to the country's GDP (National Accounts Statistics, 2013). In the days of farmers facing many uncertainties in crop production due to various factors, animal husbandry offers a cushion to protect the farmers from such pressures. Animal husbandry has evolved as an age old activity in our country. It is carried in a traditional way. With the advent of modern science and technology as well as economic liberalization, globalization and market factors many changes are seen in animal husbandry sector also. This is mainly in the form of subsistence farming to commercialized farming, extensive to intensive farming etc. Still, Animal husbandry is largely an allied and complimentary activity to agriculture. Most of the time, feeds coming from agriculture form main source of feed for animals also. An upset with agriculture, many a times affects animal husbandry as well. To ameliorate such happening, many alternative animal husbandry practices are being tried. Rearing of Mudhol hound dogs is one such promising activity to develop into a rural enterprise. India has got a vast repository of 
domestic and companion animal resources. Dog has been the important companion animal since time immemorial. India has the privilege of having excellent dog breeds like Mudhol Hound, Rajapalayam, Chippiparai, etc.

Mudhol hound is a pride dog breed of India and Karnataka. They are reared mainly in Bagalkot and Bijapur district of north Karnataka by villagers. It is mainly a hunting dog. They are elegant, graceful and courageous. One important thing that distinguishes them from other common exotic breeds like German Shephard, Labrador, Doberman etc. is their adaptability and coexistence with the rural agrarian system. Common household food can be feed to Mudhol hound dog as well they do not require much sophisticated bedding like other exotic dogs and they can adopt to hot climate of our country. In cities, they are also reared as a pet animal. It is a prolific animal. It can give birth to young ones twice a year. Each time can deliver 4-8 puppies. Each puppy costs between Rs. 5000 to 10000/-. One female dog can generate income more than Rs. 50,000/- a year. They are in great demand as pet, show, companion, hunting, loyal and guarding animals. Sayeed (2015), Described Mudhol hound as an indigenous dog breed that uplifts marginalised communities by providing them with a means of livelihood. Sai (2015) reported for a daily wage laborer Mudhol Hound dog breeding supplemented his income by rearing dogs. With Mudhol hound dog rearing, that person was able to have house of his own, send his two children to school and have a farm for his Hounds.

\section{Materials and Methods}

The study was carried out during the year 2015-2016 at Animal Husbandry Polytechnic, Shiggaon, district - Haveri of Karnataka. One female Mudhol hound dog that is reared at the polytechnic was taken for study. The income from the individual female dog was recorded and feedback taken from local farmers regarding importance of Mudhol hound dog in this study is presented.

\section{Results and Discussion}

One male and one female Mudhol hound puppies were brought from Canine Research and Information Center, Thimmapur, Bagalkot of Karnataka Veterinary, Animal and Fisheries Sciences University, Bidar. The female pup attained maturity at the age of one year and conceived. After 60 days of gestation period, it delivered 5 puppies 3 female and 2 male. All the puppies survived till the weaning age of 45 days. After 45 days, 4 puppies were sold to farmers at a predetermined price of Rs 5500/for one female pup, Rs. 6500/- for one male pup and Rs. 11000/- for a pair of male and female puppies. One female pup was retained at the institute for future breeding programmes. The female dog again came to oestrous after 6 months of previous whelping (delivery) and got conceived. Second time it delivered 5 puppies. They were also sold at the age of 45 days. An amount of Rs. 50500/was collected from sale of 9 puppies in one year i.e. from March, 2016 to December, 2016. An asset in the form of a female pup was kept with the polytechnic.

So in all, amount collected from sale of puppies was Rs 50,500/-. One female puppy that was retained also came to maturity at the age of one year and got conceived. So, it can safely be said that an amount of more than Rs $56,000 /-$ be earned by one female Mudhol hound dog per year. Total expenditure for maintaining one dog was Rs. 12953/-(Table 1). Hence, a net income of more than Rs. $44,000 /$ - can be earned per year from rearing of one female dog. This margin of profit appears to be underestimating when reared by the farmers themselves. Because cost of many food ingredients would be greatly reduced by 
offering many of the daily dietary items of the farmer households. And also, puppies can be sold at a price much higher than that - fixed at the institute- at a private level. In the current study, male dog at the polytechnic was used for servicing. It is very common to see that whose so ever male dog is left for breeding a female dog, one pup in the litter is to be given as royalty to the owner of male dog. Hence, male dog reared can also be used to obtain pedigreed puppies that have economic value.

Table.1 Expenditure for maintaining one dog

\begin{tabular}{|l|c|c|c|c|}
\hline \multicolumn{1}{|c|}{ Items } & Qty per day & $\begin{array}{c}\text { No. of days fed } \\
\text { in a year }\end{array}$ & Price & Amount(Rs.) \\
\hline Rotis & 2 & 365 & 1.5 & 1095 \\
\hline Cereal gruel & 0.1 & 365 & 20 & 730 \\
\hline Eggs & 0.5 & 365 & 3 & 547 \\
\hline Chicken waste & - & 100 & 5 & 500 \\
\hline Pedigree & 0.075 & 365 & 150 & 4106 \\
\hline Milk & 0.5 & 365 & 30 & 5475 \\
\hline $\begin{array}{l}\text { Medical care and } \\
\text { vaccinations }\end{array}$ & - & - & - & 500 \\
\hline Total & & & & $\mathbf{1 2 9 5 3}$ \\
\hline
\end{tabular}

In the current investigation, feed back from farmers who purchased the puppies was taken. One of the farmer from Hanshi village, Haveri taluk said that Mudhol hound dog was their lifeline, because they were protecting their farm from wild animals especially monkeys, wild pigs, birds and other animals which was thought as equal the work of two labours per day. Most of the farmers said Mudhol dogs were like their family member and if treated with kindness and respect can make a most loyal companion. These farmers are also thinking of breeding Mudhol dogs and develop his own business in the form of selling puppies.

Some of the important things to be noted in this study are

1. The female dog in two whelpings delivered 5 puppies each. In subsequent whelping, number of puppies is expected to be increased around 6 to 10 per whelping.
2. Cost of rearing can be reduced markedly by feeding available local household food items by the farmers.

3. There is a scope to sell the puppies at higher prices.

4. All these things can make one presume that one female Mudhol hound dog can generate a net profit of Rs 50 to 60 thousand per year which is more than income that can be generated by a high yielding cow, equals to the income generated by crop production of 2-3 acres of land.

The findings of present study conclude that, an income of more than Rs. 50000/- can be earned by a farmer by rearing one female Mudhol hound dog, which can be still increased by reducing the cost of feed and increasing the sale price of puppies. With the knowledge of entrepreneurship building, proper marketing strategies and adopting 
scientific dog rearing practices, a farmer can develop an enterprise of Mudhol hound dog rearing in rural areas.

\section{References}

National Accounts Statistics-2013 (2016); as quoted in NDDB webpage http://www.nddb.org/information/stats /GDPcontrib

Sai, Nidhi C (2015): We are the Hounds, web page

http://www.iijnm.org/mastersproject2 015/mudhol-we-are-the-hounds2015.html

Sayeed, V.A., (2015): The hounds of Mudhol, Front line, June 26, 2015.

\section{How to cite this article:}

Shambhulingappa, B.G., K. Vasudeva Naik and Sureshkumar. 2018. Mudhol Dog Rearing - A Novel Approach to Rural Enterprenurship. Int.J.Curr.Microbiol.App.Sci. 7(08): 2692-2695. doi: https://doi.org/10.20546/ijcmas.2018.708.280 